\title{
The Microbial Degradation of Crude Mineral Oils at Sea
}

\author{
By P. D. GILBERT AND I. J. HIGGINS \\ Biological Laboratory, The University, Canterbury, Kent CT2 $7 \mathrm{NJ}$
}

(Received 17 February 1978; revised 20 April 1978)

\begin{abstract}
A new experimental procedure and robust equipment have been developed for studying oil degradation at sea and the system has been proved under harsh environmental conditions. The degradation of three weathered crude oils, differing substantially in composition, has been examined under both winter and late spring conditions. The oils were an Athabasca synthetic crude, its parent sand tar and a North Sea Forties crude. Composition had a major effect on the extent and rate of loss of oil from the system, the lighter oils disappearing more rapidly. After $40 \mathrm{~d}$ at sea at a mean temperature of $5{ }^{\circ} \mathrm{C}$, only $16 \%$ of the synthetic crude remained compared with $47 \%$ and $85 \%$ of the Forties crude and sand tar respectively. At a mean temperature of $12{ }^{\circ} \mathrm{C}$, average degradation rates were about three times those at $5{ }^{\circ} \mathrm{C}$. At both temperatures, a mixed bacterial population involved in the degradation process was isolated from each oil. For the Forties crude and synthetic crude, the saturate fraction was degraded most rapidly, whilst in the sand tar, this fraction was not degraded as rapidly as the monoaromatic fraction.
\end{abstract}

\section{INTRODUCTION}

There have been few studies of crude oil degradation at sea (e.g. Olivieri et al., 1976; Gibbs \& Davies, 1975; Hughes \& McKenzie, 1975, 1976) or under simulated field conditions (e.g. Kator et al., 1971; Horowitz \& Atlas, 1977). Such work is necessary to test the validity of extrapolating the results of laboratory studies (Atlas \& Bartha, 1973; Colwell \& Walker, 1977) to the natural environment. In situ studies have been hampered by technical problems inherent in maintaining oil samples in the sea. This paper describes the development of equipment suitable for such work and data obtained by its deployment in an estuary.

\section{METHODS}

Preparation of oil samples and their exposure to the environment. Three oils were chosen for study: a North Sea Forties crude, an Athabasca synthetic crude and its parent sand tar (gifts from B.P. Petroleum). The Forties crude and synthetic crude were weathered by sparging with nitrogen for $24 \mathrm{~h}$ at room temperature. The sand tar was allowed to weather slowly over several months at room temperature without sparging. Cellulose acetate/cellulose nitrate Millipore filters (pore size $8 \mu \mathrm{m}, 47 \mathrm{~mm} \mathrm{diam}$.) were the most favourable support for the oil, allowing a thin film to be evenly absorbed over a large area. Prior to absorption, the Forties crude and sand tar were diluted with carbon tetrachloride to reduce viscosity and facilitate even absorption. The synthetic crude was absorbed evenly without dilution. The masses of Forties crude and synthetic crude absorbed on the filters were similar; with the sand tar, viscosity problems only permitted absorption of about $90 \%$ of this mass. All oiled filters contained 110 to $130 \mathrm{mg}$ oil.

The oiled filter papers were inserted through a slit into plastic practice golf balls such that they formed an equatorial diaphragm. The balls were re-sealed with a hot knife and placed in the apparatus shown in Fig. 1. The floating equipment was then attached by lines to a navigation buoy in the Medway estuary (Fig. 1). In this way samples were maintained at the water surface and free interchange with the environment was facilitated. Samples were withdrawn via the sampling port and immediately placed in a $500 \mathrm{mI} \mathrm{screw-cap}$ polythene container filled with sea water at the same time. Analysis was initiated within $2 \mathrm{~h}$ of sampling. 
Analysis of oils after exposure to the environment. Filters were collected at intervals, discs (15 mm diam.) were cut out and extracted twice with $1 \mathrm{ml}$ carbon tetrachloride and the extracts were pooled. The extracted oil was examined in a Perkin Elmer 237 infrared spectrometer using a potassium bromide liquid cell of path length $0.5 \mathrm{~mm}$. The sum of the peak heights at $3.38,3.42$ and $3.50 \mu \mathrm{m}$ (representing $\mathrm{CH}, \mathrm{CH}_{2}$ and $\mathrm{CH}_{3}$ stretching frequencies, respectively) was taken as a quantitative measurement of the amount of oil (Simrad et al., 1951). A standard curve of mass versus sum of these peak heights was constructed for each unexposed weathered oil by preparing a series of filters with decreasing masses of oil absorbed and subjecting them to the extraction and spectroscopic procedures described above. In the case of filters that had been retrieved from the environment, where possible, two $15 \mathrm{~mm}$ diam. discs were cut from each to check for uniformity of degradation over the filter.

Non-biological leaching controls. These controls were carried out at both 4 and $13{ }^{\circ} \mathrm{C}$. Oiled filter discs ( $15 \mathrm{~mm}$ diam.) were autoclaved and placed in 21 conical flasks containing $600 \mathrm{ml}$ of sterile aged sea water and ampicillin $\left(0 \cdot 11 \mathrm{mg} \mathrm{ml}^{-1}\right)$. Flasks were shaken on an orbital shaker and the oil remaining on the discs was extracted and quantified by infrared spectroscopy. Sterility checks were made using sea water nutrient agar plates.

Liquid chromatography of oil samples. This was effected using a dual phase alumina and silica gel column (Horowitz \& Atlas, 1977).

Phosphate and nitrate assays. Phosphate was measured by the method of Strickland \& Parsons (1965), and nitrate was determined using a Technicon autoanalyser (no. 174-74E; Technicon Instrument Co., Basingstoke, Hants) according to the manufacturer's instructions.

Isolation of microbial populations. On recovery of a filter from the environment, a $15 \mathrm{~mm}$ diam. disc was cut, placed in $10 \mathrm{ml}$ of aged sterile sea water containing six $2 \mathrm{~mm}$ diam. glass beads, and shaken for $5 \mathrm{~min}$ at 800 oscillations $\mathrm{min}^{-1}$ on a wrist-action flask shaker to free organisms from the filter. This method proved superior to sonication or shaking in the absence of beads. Cell suspensions were plated on nutrient agar (Oxoid) prepared using aged sea water/distilled water $(3: 1, \mathrm{v} / \mathrm{v})$. To test for the ability to degrade crude oil, single colonies were plated on 'oil agar'. This consisted of a minimal salts base and trace elements (MulkinsPhillips \& Stewart, 1974) to which $1.5 \%$ (w/v) Oxoid no. 3 agar was added. Poured plates were dried for several days at room temperature before coating the agar surface with a mixture of weathered Forties crude and carbon tetrachloride $(1: 1, \mathrm{v} / \mathrm{v})$. Plates were only used when no trace of carbon tetrachloride vapour remained.

Microscopy of microbial populations on oiled filters. On retrieval, filters were stained for light microscopy (Anon, 1965) within $2 \mathrm{~h}$ of removal from station. This gave a good general assessment of the degree of microbial colonization. Samples of oiled filters were prepared for scanning electron microscopy (Arnold et al., 1971) and examined using a Cambridge Stereoscan 600.

\section{RESULTS}

\section{Exposure of oils to the environment}

Oiled filters were examined for even absorption of oil by cutting five $15 \mathrm{~mm}$ diam. discs from each filter, followed by extraction and quantification of the oil by infrared spectroscopy. The spectra showed that the oil had been uniformly absorbed over the filters and this was confirmed by scanning electron microscopy. The apparatus (Fig. 1) containing the oiled filters performed well on station during both winter and spring experiments. It was very robust, remaining intact after storm force 10 gales encountered during the winter period when filters were recovered after $50 \mathrm{~d}$. Enclosing filters in practice golf balls, as well as providing protection, enabled rapid withdrawal of samples. Sampling was successfully completed in moderate seas up to force $6 / 7$.

\section{Degradation of oils during a winter period (23 Dec. 76 to 9 Feb. 77)}

Four experimental units were attached to a navigation buoy (Fig. $1 d$ ). Ten oiled filters were prepared for each oil (Athabasca synthetic crude, Athabasca sand tar and Forties crude), enclosed in practice golf balls and placed in the appropriate unit. The fourth unit contained 10 blank filters enclosed in practice golf balls to assess the amount of hydrocarbon absorbed from the sea water and the microbial population supported by non-oiled filters. Filters were removed at intervals for analysis and the course of oil degradation over $50 \mathrm{~d}$ on station is shown in Fig. 2(a). Figure 2(b) shows the total numbers of viable bacteria 

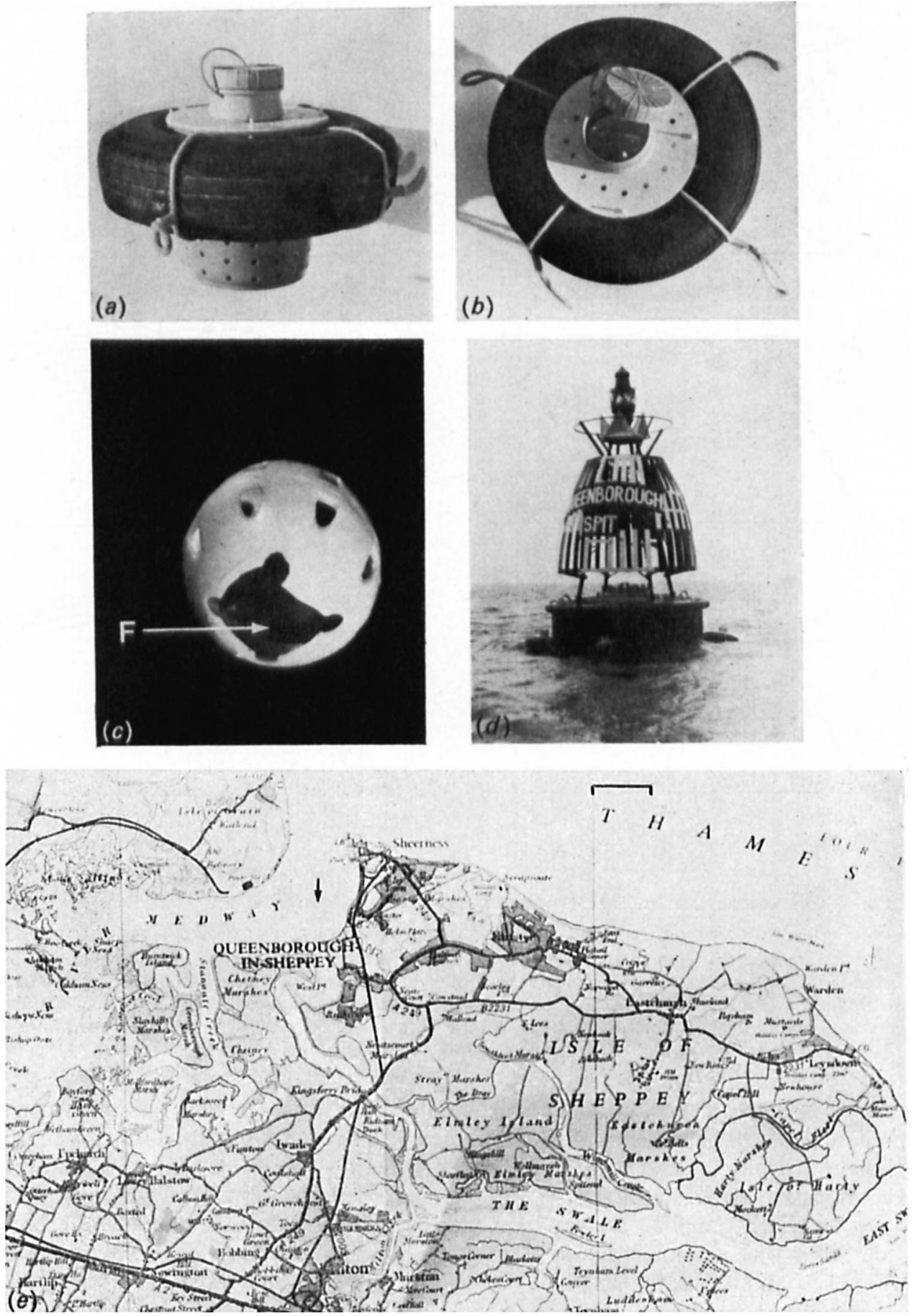

Fig. 1. ( $a, b)$ Apparatus for maintenance of oil samples at sea; (c) practice golf ball showing enclosed oiled filter, F; $(d)$ navigation buoy with experimental units attached; $(e)$ location of navigation buoy in the Medway estuary, arrowed (bar marker represents 1 mile). 


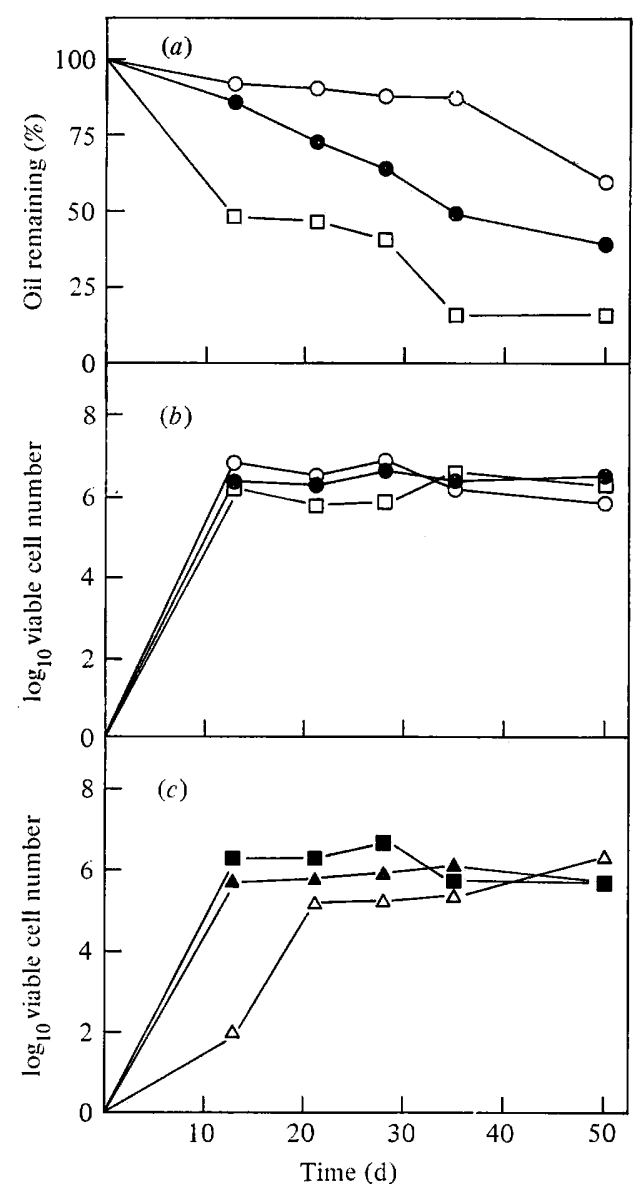

Fig. 2

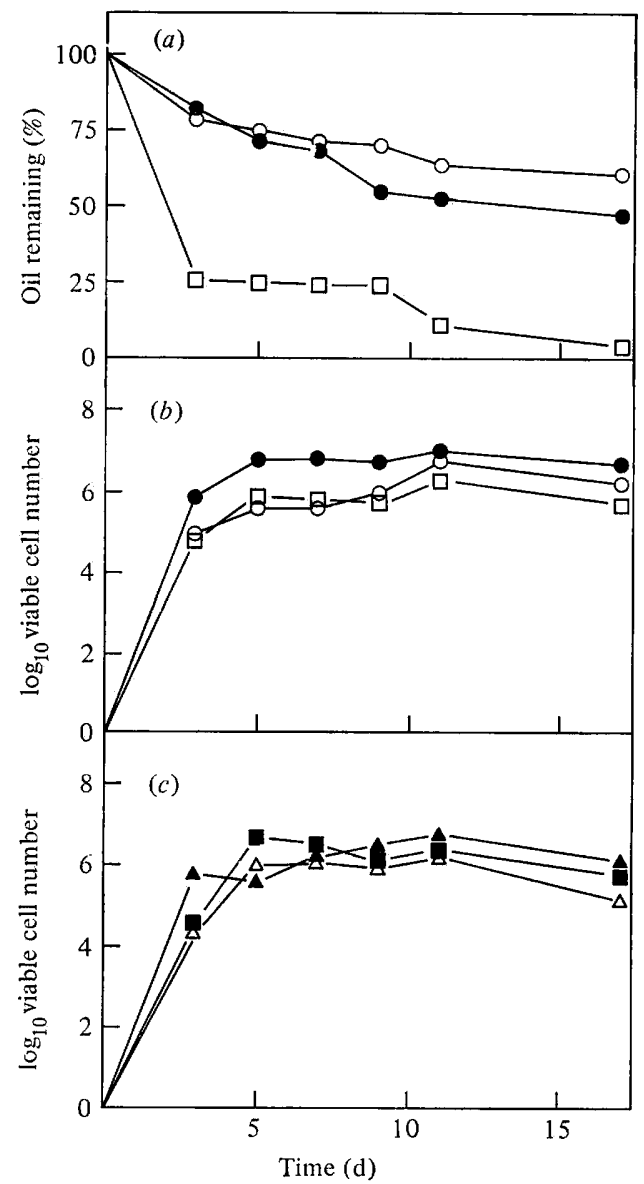

Fig. 3

Fig. 2. Oils weathered during $50 \mathrm{~d}$ exposure at sea at a mean temperature of $5{ }^{\circ} \mathrm{C}$.

Fig. 3. Oils weathered during $17 \mathrm{~d}$ exposure at sea at a mean temperature of $12^{\circ} \mathrm{C}$.

In both figures: (a) Time course for degradation of oils: $\bigcirc$, sand tar; $\bullet$, Forties crude; $\square$, Athabasca synthetic crude. (b) Total numbers of viable bacteria isolated per $15 \mathrm{~mm}$ diam. disc of oiled filter for each oil during exposure: $\bigcirc$, sand tar; - , Forties crude; $\square$, Athabasca synthetic crude. (c) Numbers of viable bacteria isolated per $15 \mathrm{~mm}$ diam. disc of oiled filter for three strains isolated from Forties crude filters during exposure: $\boldsymbol{\square}$, strain $1 ; \boldsymbol{\Delta}$, strain $2 ; \triangle$, strain 3 .

supported by each oil for a $15 \mathrm{~mm}$ diam. disc of filter. In each case the total bacterial population could be resolved into three colonially and microscopically distinct strains, all capable of growth on oil agar. Figure $2(c)$ shows the relative viable cell numbers of these three strains supported by the Forties crude; similar patterns were observed for the other two oils. At each sampling the surface water temperature was taken and the phosphate concentration was determined. Both parameters showed little variation; the mean temperature was $5{ }^{\circ} \mathrm{C}$ and the mean phosphate concentration, $4.8 \mu \mathrm{M}$. Laboratory controls to assess the extent of non-biological loss of oil from filters remained sterile and gave similar results at both 4 and $13{ }^{\circ} \mathrm{C}$. The three oils displayed the same patterns of loss from the filters being essentially complete within the first $7 \mathrm{~d}$, whereafter no appreciable further loss occurred. The extent of the leaching was different for each oil: 50,10 and $7 \%$ was lost for the synthetic crude, Forties crude and the sand tar, respectively. 

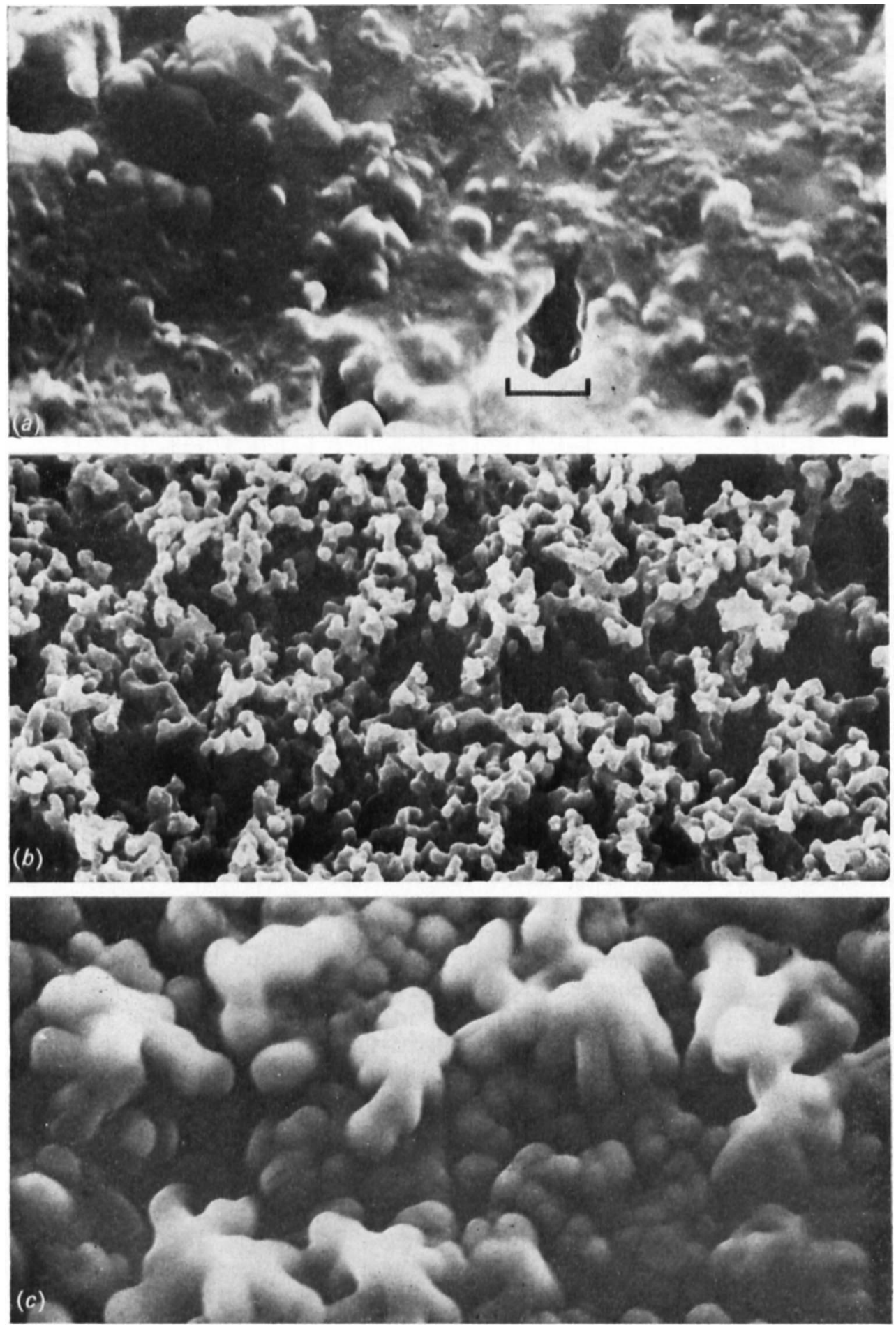

Fig. 4. Scanning electron micrographs: $(a)$ bacteria colonizing the surface of an oiled filter coated with weathered Forties crude after $5 \mathrm{~d}$ exposure at sea at a mean temperature of $12^{\circ} \mathrm{C} ;(b)$ a filter before coating with oil; $(c)$ a filter coated with Forties crude but unexposed to the environment. Bar marker represents $4 \mu \mathrm{m}$. 


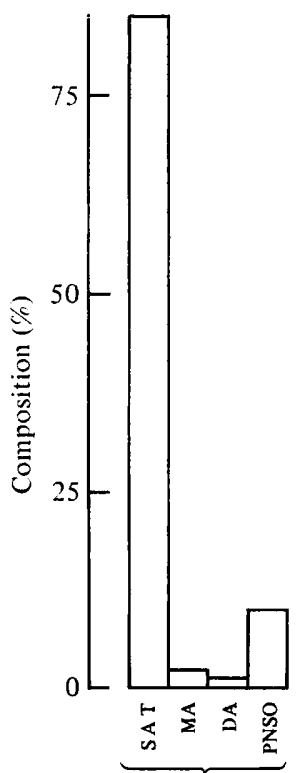

(a)

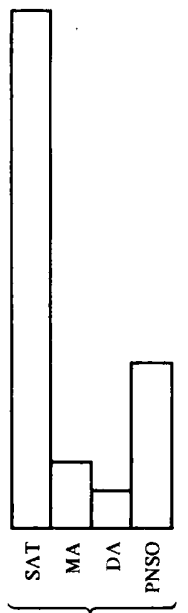

(b)

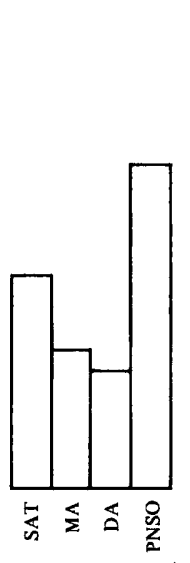

(c)

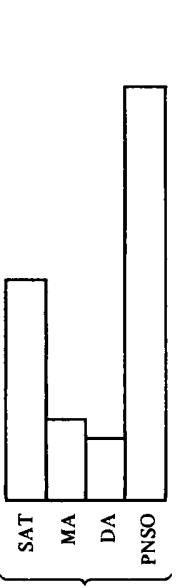

$(d)$

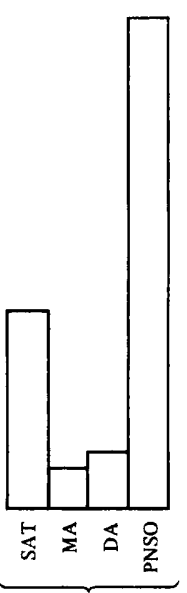

(e)

Fig. 5. Fractional compositions of weathered and partially degraded oils: (a) Athabasca synthetic crude; (b) Forties crude; (c) Forties crude after $17 \mathrm{~d}$ exposure at sea at a mean temperature of $12{ }^{\circ} \mathrm{C} ;(d)$ sand tar; $(e)$ sand tar after $17 \mathrm{~d}$ exposure at sea at a mean temperature of $12{ }^{\circ} \mathrm{C}$. SAT, Saturate fraction; MA, monoaromatic fraction; DA, diaromatic fraction; PNSO, polycyclic and nitrogen, sulphur and oxygen containing compounds.

\section{Degradation of oils during a late spring period (2 May 77 to 19 May 77)}

The four experimental units were attached to the buoy as before, 10 samples being placed in each unit. Figure $3(a)$ shows the course of oil degradation during the $17 \mathrm{~d}$ on station and Fig. $3(b)$, the total viable bacterial population supported by each oil per $15 \mathrm{~mm}$ diam. disc of oiled filter. As for the winter period, three colonially and morphologically distinct bacterial strains were isolated from each oil; all were capable of growth on oil agar. Figure 3 (c) shows the relative numbers of each strain for the Forties crude; the other two oils showed similar patterns. The surface water temperature and phosphate concentration varied little over the experimental period at the times of sampling, the mean temperature being $12{ }^{\circ} \mathrm{C}$ and the mean phosphate concentration, 5.0 $\mu \mathrm{M}$. Figure $4(a)$ shows a scanning electron micrograph of bacteria colonizing the surface of an oiled filter impregnated with Forties crude, which had been exposed at sea for $5 \mathrm{~d}$ at $12{ }^{\circ} \mathrm{C}$. Figure $4(b, c)$ show a nonoiled filter and a filter impregnated with Forties crude, respectively, for comparison. Oiled filters from laboratory controls showed no change in surface appearance over $5 \mathrm{~d}$. At the end of the spring period, the remaining oiled filters were extracted with carbon tetrachloride, the extracts were pooled and column chromatographic analysis was carried out for each oil. The fractional compositions of the original weathered oils and those of the oils after $17 \mathrm{~d}$ exposure at sea are shown in Fig. 5. In the case of the synthetic crude, insufficient oil was recovered after $17 \mathrm{~d}$ to permit accurate analysis.

All of the bacterial isolates from both experimental periods were facultatively psychrophilic Gram-negative rods. At both temperatures the blank filters exposed at sea supported only a low population (less than $10^{2}$ cells per $15 \mathrm{~mm}$ diam. filter disc) compared with the oiled filters. The nitrate concentration in samples never exceeded $60 \mu \mathrm{M}$. 


\section{DISCUSSION}

Whilst the equipment proved successful in maintaining oil samples at sea, its nature probably minimizes the effects of non-biological chemical reactions involving free radicals as little light penetrates the apparatus. The loss of oil from filters during exposure at sea will, nevertheless, include both biological and non-biological components. The probable extent of non-biological leaching of oil from filters was estimated using laboratory controls. It may be that association of bacteria and extracellular slime with the filters reduces this loss. Extensive growth of oil-degrading bacteria on the oil-impregnated filter is consistent with a large element of true biodegradation being represented in the oil loss data. However, microbial growth on the oil may mediate its loss from filters by production of natural surfactants and the formation of more polar and hence more hydrophilic partial breakdown products. In the latter case, further degradation is likely. We have been unable to devise satisfactory experiments to determine the relative importance of these processes. Therefore, the term 'biodegradation' is used somewhat loosely in this paper to encompass that loss of oil from the filters which is dependent on the presence of bacteria.

The three oils under study differ substantially in fractional composition. The sand tar is a heavy, viscous oil, low in saturates, high in polycyclic and nitrogen, sulphur and oxygen containing compounds (PNSO) and relatively high in aromatics. The Athabasca synthetic crude derived from the sand tar is of very different composition being high in saturates, low in PNSO compounds and in aromatics. The North Sea Forties crude is intermediate between these two extremes. It has been well substantiated in the laboratory (Walker et al., $1976 b$ ) that the fractional composition of an oil influences the biodegradation rate, yet it was not known how this influences degradation rates in the environment. This study shows that as the saturate fraction of the oil decreases and the PNSO fraction increases, the biodegradation rate decreases. Hence at both times of the year (winter and late spring), the order of biodegradation rates was synthetic crude $>$ Forties crude $>$ sand tar. At the end of the spring period, the column chromatographic analysis showed the extent of degradation for each fraction. In the case of the synthetic crude, insufficient oil could be recovered after $17 \mathrm{~d}$ for analysis indicating that the saturate fraction underwent the greatest degradation as this constitutes over $80 \%$ of the oil. In the Forties crude, the saturate fraction underwent the greatest degradation, the PNSO fraction increasing relative to that in the original oil. Such increases in this fraction during microbial growth in laboratory experiments have been reported previously (Walker et al., 1975, 1976a). In the sand tar, the monoaromatic fraction underwent the most degradation both in absolute terms and as a proportion of the whole oil. The saturate fraction was the next most extensively degraded and, as with the Forties crude, there was a relative increase in the PNSO fraction. For each oil, the extent of degradation after $50 \mathrm{~d}$ at a mean temperature of $5^{\circ} \mathrm{C}$ was reached in $17 \mathrm{~d}$ at a mean temperature of $12{ }^{\circ} \mathrm{C}$, representing an approximate threefold increase in the rate for a rise of $7{ }^{\circ} \mathrm{C}$. This concurs with $Q_{10}$ values of approximately 3 calculated for organisms growing on crude oil in the laboratory (Gibbs et al., 1975). Temperature did not affect the extent of the non-biological loss found in the laboratory controls; this loss may in part represent the solubilization of the more polar compounds, which itself is part of the weathering process. The high degree of leaching of the synthetic crude $(50 \%$ within $7 \mathrm{~d})$ would explain the high initial loss of oil from the filters on station. The microbial populations supported by the $15 \mathrm{~mm}$ diam. discs of oiled filters rose to maximum levels within $13 \mathrm{~d}$ at $5{ }^{\circ} \mathrm{C}$ and $5 \mathrm{~d}$ at $12{ }^{\circ} \mathrm{C}$; these were maintained with little fluctuation for the rest of the experimental period. This was true for each of the three oils at both temperatures. The similarity of the bacterial numbers isolated from each oil at both temperatures suggests that there is some factor limiting the number of bacteria accommodated by the oiled filter; this is probably the surface area available for colonization. Absorption of oil to the filters should not affect the bacterial colonization rate of the oil, as the surface presented to the bacterium is that of the 
coating oil film rather than the filter material. The blank filters exposed at sea supported only a very low population compared with the oiled filters, which suggests that the support for the oil films does not substantially affect colonization.

Whilst the data in this paper indicate the relative degradation rates of three oils in the sea, they have been obtained from only one estuarine location in late spring and winter in a temperate climate. Nevertheless such in situ data is very scarce and there is no reason to believe that the site chosen is atypical for such an environment. The actual location of the experimental equipment (Fig. $1 e$ ) was in an open stretch of a highly saline estuary, the salinity variation between low and high tides being very small, 33 to 34 ( $\mathrm{S} \%$ 100) (unpublished observations). It is heavily used by shipping with an oil refinery approximately 1 mile upstream from the buoy but is otherwise not heavily industrialized. The tidal flow at the site is about 3 knots.

Since biodegradation rates may well be determined in part by the availability of phosphate and nitrate, the concentration of these ions in the region of the buoy was measured during the experiments (unpublished observations). The amounts present varied little and were of the same order as those commonly found for inshore waters. Hence biodegradation rates were not stimulated by elevated phosphate and nitrate levels which occur in some polluted locations.

P. D. Gilbert thanks the NERC for a research studentship. We are grateful for the assistance and co-operation of Captain G. Baskerville of the Medway Ports Authority without whom this work would not have been possible. Drs P. L. Sturla and L. J. Barnes of Shell Research Ltd, Sittingbourne, kindly carried out the nitrate assays.

\section{REFERENCES}

ANON (1965). Techniques for Microbiological Analysis, Millipore booklet ADM 40, p. 7. Bedford, Mass., U.S.A.: Millipore Corporation.

Arnold, J. D., Berger, A. E. \& Allison, O. L. (1971). Some problems of fixation of selected biological samples for S.E.M. examination. Scanning Electron Microscopy 1, 249-256.

Atlas, R. M. \& Bartha, R. (1973). Fate and effects of petroleum in the marine environment. Residue Reviews 49, 49-85.

Colwell, R. R. \& Walker, J. D. (1977). Ecological aspects of microbial degradation of petroleum in the marine environment. $C R C$ Critical Reviews in Microbiobiology 5, 423-445.

GibBs, C. F. \& Davies, S. J. (1975). The effects of weathering on crude oil residues exposed at sea. Water Research 9, 275-285.

Gibes, C. F., Pugh, K. B. \& Andrews, A. R. (1975). Quantitative studies on marine biodegradation of oil. II. Effect of temperature. Proceedings of the Royal Society B188, 83-94.

Horowitz, A. \& Arlas, R. M. (1977). Continuous open flow through system as a model for oil degradation in the Arctic ocean. Applied and Environmental Microbiology 33, 647-653.

Hughes, D. E. \& McKenzie, P. (1975). The microbial degradation of oils in the sea. Proceedings of the Royal Society B189, 375-390.

Hughes, D. E. \& McKenzie, P. (1976). Microbial degradation of oils and petrochemicals in the sea. In Microbiology in Agriculture, Fisheries and Food, Society for Applied Bacteriology Symposium Series 4, pp. 91-107. Edited by F. A. Skinner \& J. G. Carr. London: Academic Press.

Kator, H., Oppenheimer, C. H. \& Miget, R. J.
(1971). Microbial degradation of a Louisiana crude oil in closed flasks and under simulated field conditions. In Proceodings of the Conference on Prevention and Control of Oil Spills, pp. $287-$ 296. Washington, D.C.: American Petroleum Institute.

Mulkins-Phillips, G. J. \& Stewart, J. E. (1974). Effect of environmental parameters on bacterial degradation of bunker oil, crude oils and hydrocarbons. Applied Microbiology 28, 915-922.

Olivieri, R., Bacchin, P., Robertiello, A., Oddo, N., Degen, L. \& Tonolo, A. (1976). Microbial degradation of oil spills enhanced by a slow release fertilizer. Applied and Environmental Microbiology 31, 629-637.

Simrad, R. G., Hasegawa, I., Bandaruk, W. \& Headington, C. E. (1951). Infrared spectrophotometric determination of oils and phenols in water. Analytical Chemistry 23, 1384-1387.

Strickland, J. D. H. \& Parsons, T. R. (1965). A manual of sea water analysis. Bulletin of the Fisheries Research Board of Canada 125, 47-51.

Walker, J. D., Colwell, R. R. \& Petrakis, L. (1975). Microbial petroleum degradation: application of computerized mass spectrometry. Canadian Journal of Microbiology 21, 1760-1767.

Walker, J. D., Colwell, R. R. \& Petrakis, L. $(1976 a)$. Biodegradation rates of components of petroleum. Canadian Journal of Microbiology 22, 1209-1213.

Walker, J. D., Petrakis, L. \& Colwell, R. R. $(1976 b)$. Comparison of biodegradability of crude and fuel oils. Canadian Journal of Microbiology 22, 598-602. 